\title{
Infrared Spectra of High Polymers
}

\author{
Part IX. Polyethylene Terephthalate \\ C. Y. LIang* and S. Krimm \\ Harrison M. Randall Laboratory of Physics, University of \\ Michigan, Ann Arbor, Michigan
}

\begin{abstract}
Infrared spectra of polyethylene terephthalate and three of its deuterated analogs have been obtained in the region of 70 to $3600 \mathrm{~cm}^{-1}$, polarized spectra having been obtained down to $330 \mathrm{~cm}^{-1}$. On the basis of analysis of the predicted spectrum, and with the aid of data from benzene and substituted benzenes, a complete assignment of the spectrum has been made. This assignment suggests a modification of the proposed chain structure of this polymer. It also leads to the conclusion that the changes in the spectrum which occur upon erystallization of the polymer are not associated with different isomeric forms of the $-\mathrm{OCH}_{2} \mathrm{CH}_{2} \mathrm{O}$-- portion of the chain, but rather with changes in the symmetry and resonance characteristics of the substituted benzenoid ring framework.
\end{abstract}

\section{INTRODUCTION}

The infrared spectrum of polyethylene terephthalate, $\left(-\mathrm{OCH}_{2} \mathrm{CH}_{2} \mathrm{OOCC}_{6}\right.$ $\left.\cdot \mathrm{H}_{4} \mathrm{CO}-\right)_{n}$, has been the subject of fairly extensive investigation. Early efforts (1) were concerned with obtaining the polarized spectrum in the region above $700 \mathrm{~cm}^{-1}$, and with the interpretation (2) of some of its salient features. Extension of the spectral region down to about $100 \mathrm{~cm}^{-1}$ was undertaken (3) in order to permit a more complete analysis. The first attempt at making an assignment of bands in the infrared spectrum was due to Miller and Willis (4), who investigated the region of 700 to $1800 \mathrm{~cm}^{-1}$ with polarized radiation and oriented samples. The $2600-$ to $3600-\mathrm{cm}^{-1}$ region was subsequently studied (5). While a deeper understanding of the spectrum was achieved, a complete and satisfactory set of assignments did not emerge from this work. Subsequent efforts were concentrated mainly on elucidating the changes occurring in the spectrum as a result of crystallization. Cobbs and Burton (6) presented spectra indicating pronounced enhancement of absorption at 1340 and $972 \mathrm{~cm}^{-1}$ upon crystallization of the polymer, as well as smaller changes in some of the other bands. This was

\footnotetext{
* Present address: Research and Development Division, American Viscose Corporation, Marcus Hook, Pennsylvania.
} 
confirmed by Miller and Willis ( 7$)$, who also pointed out that some bands are to be specifically associated with the amorphous phase. The elucidation of the structure of crystalline polyethylene terephthalate by Daubeny et al. (8) provided a means for understanding a possible basis for these changes. Ward $(9,10)$ suggested that they arise as a result of rotational isomerism in the $-\mathrm{OCH}_{2}$ - $\mathrm{CH}_{2} \mathrm{O}$ - portion of the chain, bands at $1470,1340,975$, and $850 \mathrm{~cm}^{-1}$ being attributable to the trans configuration of the $\mathrm{CH}_{2}$ groups in the crystalline regions, while bands at $1445,1370,1045$, and $900 \mathrm{~cm}^{-1}$ are to be associated with the gauche configuration of the $\mathrm{CH}_{2}$ groups which is presumably to be found in the amorphous regions. This interpretation appeared to receive confirmation from work on linear and cyclic oligomers of polyethylene terephthalate $(10,11)$. Although end group assignments have been made (12), and preliminary reports on the assignments of several of the polymer modes have appeared $(13,14)$, the first attempt at a detailed assignment in terms of some of the normal modes of the molecule was due to Tobin (15). Despite this thorough study, many aspects of the interpretation of the spectrum remained uncertain.

That ambiguities of interpretation and assignment still exist is not surprising, since the polyethylene terephthalate spectrum is one of the most complex yet submitted to a detailed analysis. The simplifications of a factor group analysis (16-18) are not very helpful because of the large number of atoms in the unit cell. In order to assist in making assignments we have, in addition to obtaining far infrared and polarization data, obtained the spectra of various deuterated species of polyethylene terephthalate. A preliminary report on the latter has already appeared (19). In this paper we wish to examine this and other data in an effort to make a complete assignment of the spectrum.

\section{EXPERIMENTAL RESULTS}

The techniques used in the present work have been described in a previous paper (17). The film samples of normal and deuterated polyethylene terephthalate were supplied to us by E. I. du Pont de Nemours and Company. Orientalion was introduced by stretching or rolling. The spectra of the various polymers are shown in Figs. 1 to 4 . The numbers adjacent to the curves represent specimen thickness in inches. In the polarized spectra between 330 and $3600 \mathrm{~cm}^{-1}$, the solid curve represents absorption with the electric vector perpendicular to the orientation direction and the broken curve that with the electric vector parallel to this direction. Bands are designated $\sigma$ or $\pi$ according as the maximum absorption occurs with perpendicular or parallel polarized light, respectively.

The frequency, relative intensity, polarization, and crystalline or amorphous origin (based on the change in intensity of the band upon crystallization) of the bands in polyethylene terephthalate are listed in Table I. The assignments given in Table I will be discussed in more detail below. In Tables II to IV are 


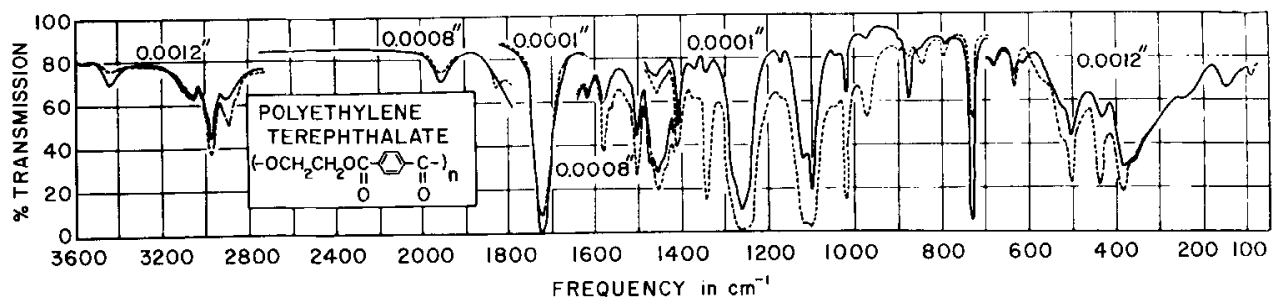

FIG. 1. Infrared spectrum of polyethylene terephthalate.

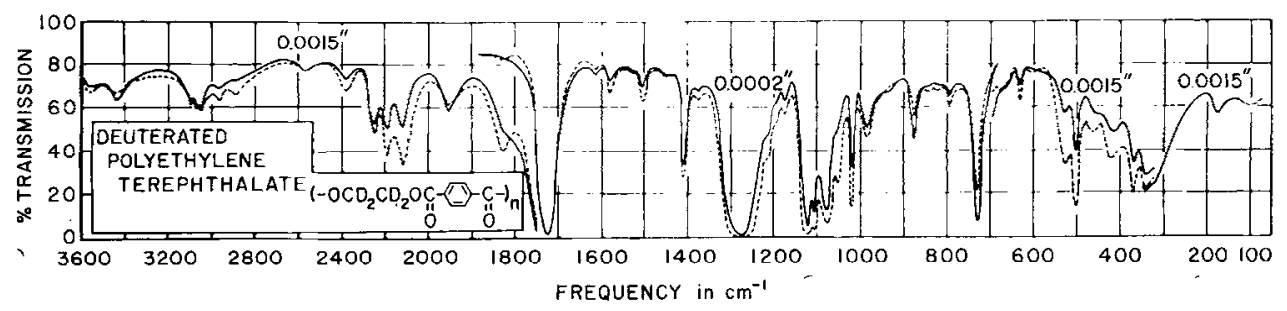

FIG. 2. Infrared spectrum of polyethylene- $D_{4}$ terephthalate.

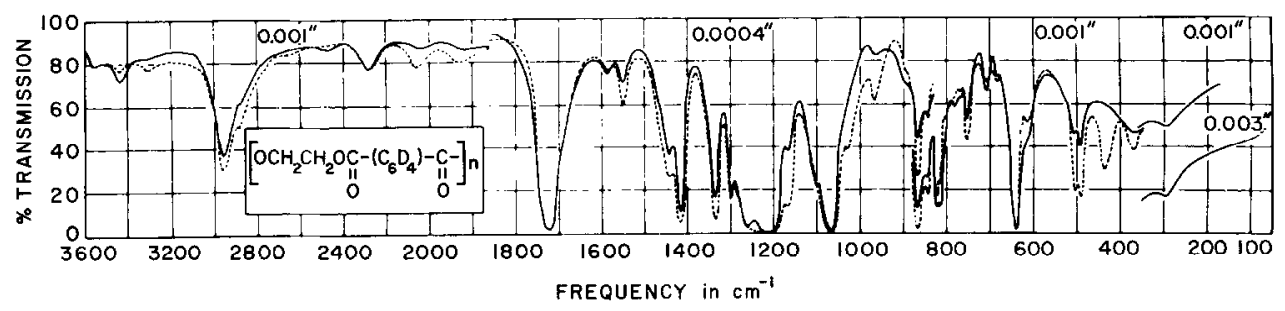

FIG. 3. Infrared spectrum of polyethylene terephthalate- $D_{4}$.

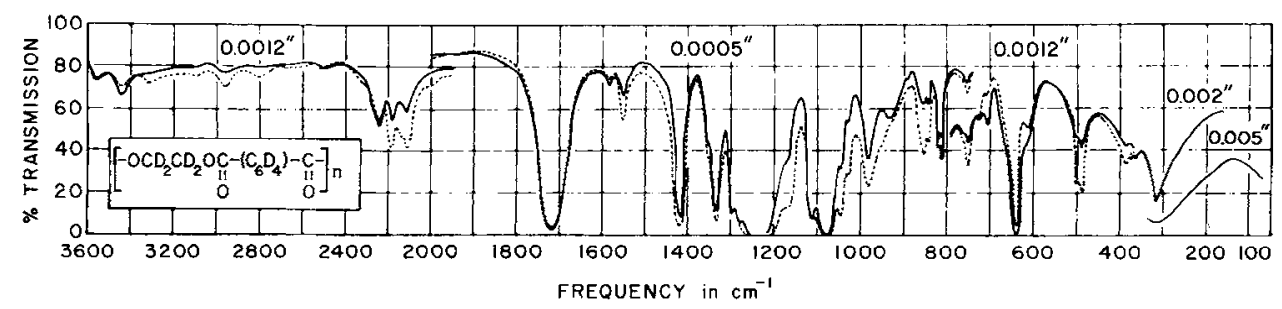

Fig. 4. Infrared spectrum of polyethylene- $D_{4}$ terephthalate- $D_{4}$. 
TABLE I

Infrared Spectrum of Polyethylene Terephthalate

\begin{tabular}{|c|c|c|c|}
\hline Frequency, $\mathrm{cm}^{-1}$ & R. I. & Polarization & Assignment* \\
\hline$\sim 95$ & vw & & Skeletal (?) \\
\hline 145 & $\mathrm{w}$ & & $\nu_{10 B}\left(B_{3 g}\right)(?)$ \\
\hline 250 & vw & & $\nu_{18 B}\left(B_{3 u}\right)$ \\
\hline 355 & w & $\sigma(?)$ & $\gamma_{r}(\mathrm{C}=\mathrm{O})$ \\
\hline 383 (c) $\dagger$ & $\mathrm{m}$ & $\pi$ & $\delta(\mathrm{COC})$ \\
\hline 430 & $\mathrm{w}$ & $\sigma$ & $\nu_{16 B}\left(B_{1 u}\right)$ \\
\hline 437 (c) & $\mathrm{m}$ & $\pi$ & $\delta(\mathrm{CCO})$ \\
\hline 502 (a) & $\mathrm{m}$ & $\pi$ & $\gamma_{w}(\mathrm{C}=\mathrm{O})$ \\
\hline 525 (a) & $\mathbf{w}$ & $\pi(?)$ & $\nu_{6, A}\left(A_{1}\right)$ \\
\hline 575 & vw & $\pi$ & $\nu_{10 B}\left(B_{3 g}: 145\right)+\nu_{16 B}\left(B_{1 u}: 430\right)=575\left(B_{2 u}\right)$ \\
\hline $613(a)$ & vw & $\sigma$ & $\nu_{5 B}\left(B_{1}\right)$ \\
\hline $633(c)$ & w & $\pi$ & $\nu_{18 B}^{\prime}+\delta(\mathrm{COC})=633$ \\
\hline 680 (a) & vw & $\sigma(?)$ & $\nu_{4}\left(B_{2}\right)$ \\
\hline $\left.\begin{array}{l}727 \\
733\end{array}\right\}$ & s & $\sigma$ & $\nu_{11}\left(B_{1 u}\right)$ \\
\hline $796(a)$ & $\mathrm{w}$ & $\pi$ & $\left\{\begin{array}{l}\gamma_{\mathrm{r}}(\mathrm{C}=\mathrm{O})+\delta(\mathrm{CCO})=792 \\
\nu_{1 \in B}+\delta(\mathrm{COC})=813\end{array}\right.$ \\
\hline $845(\mathrm{c})$ & $\mathbf{w}$ & $\pi$ & $\gamma_{r}\left(\mathrm{CH}_{2}\right)$ \\
\hline 875 & $\mathrm{~m}$ & $\sigma$ & $\nu_{17 B}\left(B_{1 u}\right)$ \\
\hline 898 (a) & vw & $\pi(?)$ & $\delta(\mathrm{COC})+\gamma_{\mathrm{w}}(\mathrm{C}=\mathrm{O})=885(?)$ \\
\hline $973(\mathrm{c})$ & $\mathrm{m}$ & $\pi$ & $\nu_{12}\left(B_{2 u}\right)$ \\
\hline 1020 & s & $\pi$ & $\nu_{18 A}\left(B_{2 u}\right)$ \\
\hline 1043 (a) & $\mathbf{w}$ & - & $\nu(\mathrm{CC})(?)$ \\
\hline $1100(a)$ & $\mathbf{s}$ & $\pi$ & $\left\{\begin{array}{l}\nu_{15}^{\prime}\left(B_{3 u}\right) \\
\nu(\mathrm{O}-\mathrm{C}) \text { (amorphous) }\end{array}\right.$ \\
\hline $1120(\mathrm{c})$ & s & $\pi$ & $\nu(\mathrm{O}-\mathrm{C})$ (crystalline) \\
\hline 1172 (a) & $\mathbf{w}$ & $\pi(?)$ & $\nu_{9 A}\left(A_{1}\right)$ \\
\hline 1245 & $\mathrm{vw})$ & & $\|$ \\
\hline 1263 & vs & $\pi$ & $\nu(\mathrm{C}-\mathrm{O})$ \\
\hline 1280 & vw) & & \\
\hline $1343(\mathrm{c})$ & s & $\pi$ & $\nu_{13}\left(B_{2 i z}\right)$ \\
\hline 1370 (a) & $\mathrm{w}$ & $\pi(?)$ & $\left\{\begin{array}{l}\nu_{2}^{\prime}\left(A_{1}\right)(?) \\
\nu_{5}\left(B_{3 g}: 978\right)+\nu_{16 A}\left(A_{u}: 404\right)=1382\left(B_{3 u}\right)\end{array}\right.$ \\
\hline 1410 & s & $\pi$ & $\nu_{5}\left(B_{3 g}: 978\right)+\nu_{16 B}\left(B_{1 u}: 430\right)=1408\left(B_{2 u}\right)$ \\
\hline 1435 & $\mathrm{vw}$ & $\pi(?)$ & \\
\hline $1455(a ?)$ & $\mathrm{m}$ & $\pi$ & $\delta\left(\mathrm{CH}_{2}\right)$ \\
\hline $1473(c)$ & w & $\sigma$ & $\left\{\begin{array}{l}\nu_{19 B}\left(B_{3 u}\right) \\
\delta\left(\mathrm{CH}_{2}\right)(?)\end{array}\right.$ \\
\hline 1504 & $\mathrm{mw}$ & $\pi$ & $\nu_{19 A}\left(B_{2 u}\right)$ \\
\hline 1563 & vw & & $\nu(\mathrm{O} \quad \mathrm{C})+\delta(\mathrm{CCO})=1557$ \\
\hline $1580(a ?)$ & mw & $\pi$ & $\nu_{8 A}\left(A_{1}\right)$ \\
\hline 1617 (a) & w & $\sigma$ & $\nu_{8 B}\left(B_{1}\right)$ \\
\hline 1724 & vs & $\sigma$ & $\nu(\mathrm{C}=\mathrm{O})$ \\
\hline 1830 & $\mathbf{w}$ & $\pi$ & $\nu_{10 A}\left(B_{2 g}: 853\right)+\nu_{17 A}\left(A_{u}: 977\right)=1830\left(B_{2 u}\right)$ \\
\hline 1955 & $\mathrm{mw}$ & $\sigma$ & $\nu_{17 A}\left(A_{u}: 977\right)+\nu_{5}\left(B_{3 g}: 978\right)=1955\left(B_{3 u}\right)$ \\
\hline 2852 & vw & $\pi(?)$ & \\
\hline 2890 & $\mathrm{vw}$ & $\pi(?)$ & \\
\hline
\end{tabular}


TABLE I-Continued

\begin{tabular}{llcl}
\hline Frequency, $\mathrm{cm}^{-1}$ & R. I. & Polarization & \multicolumn{1}{c}{ Assignment* } \\
\hline 2908 & m & $\pi$ & $\nu_{\mathrm{s}}\left(\mathrm{CH}_{2}\right)$ \\
2970 & $\mathrm{~ms}$ & $\pi$ & $\nu_{\mathrm{a}}\left(\mathrm{CH}_{2}\right)$ \\
$3012(\mathrm{c})$ & $\mathrm{ww}$ & $\pi$ & \\
$3055(\mathrm{c})$ & $\mathrm{w}$ & $\pi$ & $\nu_{20 A}\left(B_{2 u}\right)$ \\
3068 & w & $\sigma$ & $\nu(\mathrm{C}=\mathrm{O})+\nu_{13}\left(B_{2 u}\right)=3067(?)$ \\
3082 & w & $\sigma$ & $\nu_{20 B}\left(B_{3 u}\right)$ \\
3100 & w & $\sigma$ & \\
3130 & vw & - & \\
3440 & w & $\sigma$ & $2 \times \nu(\mathrm{C}=0)=3448$ \\
3560 & w & $\pi$ & $\nu(\mathrm{OH})$ (end groups $)$ \\
\hline
\end{tabular}

$*_{\nu}=$ stretching, $\delta=$ bending, $\gamma_{\mathrm{w}}=$ wagging, $\gamma_{\mathrm{r}}=$ rocking.

$\dagger(\mathrm{a})=$ amorphous, $(\mathrm{c})=$ crystalline (data from Refs. $6,7,15$, and 19 ).

TABLE II

Infrared Spectrum of Polyethylene- $D_{4}$ Terephthalate

\begin{tabular}{|c|c|c|c|c|c|}
\hline $\begin{array}{l}\text { Frequency, } \\
\qquad \mathrm{cm}^{-1}\end{array}$ & R. I. & Polarization & $\begin{array}{l}\text { Frequency, } \\
\qquad \mathrm{cm}^{-1}\end{array}$ & R. I. & Polarization \\
\hline$\sim 100$ & vw? & & 1196 & $\mathrm{vw}$ & - \\
\hline 177 & $w$ & & 1218 & $\mathrm{vw}$ & - \\
\hline 315 & vw & & 1275 & vs & $\pi$ \\
\hline 340 & $\mathrm{~m}$ & $\pi$ & 1375 & w & $\pi(?)$ \\
\hline 370 & $\mathrm{~m}$ & $\pi$ & 1408 & $\mathrm{~s}$ & $\pi$ \\
\hline 415 & & & 1450 & vw & $\pi(?)$ \\
\hline 423$\}$ & $\mathrm{mw}$ & $\pi$ & 1504 & $\mathrm{mw}$ & $\pi$ \\
\hline $464^{\prime}$ & $w$ & $\pi$ & 1526 & $\mathrm{vw}$ & - \\
\hline 502 & $\mathrm{~m}$ & $\pi$ & 1581 & $\mathrm{mw}$ & $\pi$ \\
\hline 528 & $\mathbf{w}$ & $\pi(?)$ & 1613 & $\mathrm{w}$ & $\sigma$ \\
\hline 603 & vw & $\pi(?)$ & 1724 & vs & $\sigma$ \\
\hline 633 & $\mathrm{w}$ & $\pi$ & 1828 & w & $\pi$ \\
\hline 678 & $\mathrm{vw}$ & $\pi(?)$ & 1955 & $\mathrm{mw}$ & $\sigma$ \\
\hline 728 & & & 2118 & $\mathrm{~m}$ & $\pi$ \\
\hline$(734)\}$ & $\mathrm{s}$ & $\sigma$ & 2190 & $\mathrm{~m}$ & $\pi$ \\
\hline 795 & $\mathrm{w}$ & $\pi$ & 2247 & $\mathrm{mw}$ & $\sigma$ \\
\hline 825 & $\mathrm{vw}$ & $\pi$ & 2380 & w & $\pi$ \\
\hline 844 & $\mathrm{vw}$ & $\pi$ & 2570 & $\mathrm{w}$ & $\sigma(?)$ \\
\hline 875 & $\mathrm{~m}$ & $\sigma$ & 2890 & vw & $\pi$ \\
\hline 937 & vw & $\sigma$ & 2965 & $\mathrm{vw}$ & $\pi$ \\
\hline 984 & $\mathrm{~m}$ & $\pi$ & 3055 & $\mathrm{vw}$ & $\pi(?)$ \\
\hline 1019 & $\mathrm{~s}$ & $\pi$ & 3066 & vw & $\sigma(?)$ \\
\hline 1052 & $\mathrm{mw}$ & $\pi$ & 3075 & vw & $\sigma(?)$ \\
\hline 1076 & $\mathrm{~ms}$ & $\pi$ & 3100 & vw & $\sigma$ \\
\hline 1106 & $\mathrm{~s}$ & $\pi$ & 3335 & vw & $\pi$ \\
\hline 1122 & $\mathrm{~s}$ & $\pi$ & $34 \pm 0$ & $w$ & $\sigma$ \\
\hline 1174 & $\mathrm{w}$ & $\sigma(?)$ & 3560 & $\mathrm{w}$ & $\pi$ \\
\hline
\end{tabular}


TABLE III

Infrared Spectrum of Polyethylene Terephthalate- $D_{4}$

\begin{tabular}{|c|c|c|c|c|c|}
\hline $\begin{array}{c}\text { Frequency } \\
\mathrm{cm}^{-1}\end{array}$ & R. I. & Polarization & $\begin{array}{l}\text { Frequency, } \\
\mathrm{cm}^{-1}\end{array}$ & R. I. & Polarization \\
\hline 297 & $\mathrm{w}$ & & 1166 & $\mathrm{w}$ & - \\
\hline 370 & $\mathrm{mw}$ & $\pi$ & 1215 & vs & $\pi(?)$ \\
\hline 437 & $\mathrm{~m}$ & $\pi$ & 1260 & $\mathrm{~s}$ & $\sigma(?)$ \\
\hline 490 & $\mathrm{~m}$ & $\pi$ & 1300 & $\mathrm{~m}$ & $\sigma$ \\
\hline 503 & $\mathrm{~m}$ & $\pi$ & 1335 & $\mathrm{~s}$ & $\pi$ \\
\hline 615 & $\mathrm{w}$ & $\pi$ & 1416 & $\mathrm{~s}$ & $\pi$ \\
\hline 640 & s & $\sigma$ & 1443 & $\mathrm{~m}$ & $\pi$ \\
\hline 684 & vw & $\pi(?)$ & 1551 & $\mathrm{~m}$ & $\pi$ \\
\hline 707 & w & $\sigma$ & 1586 & $\mathrm{w}$ & $\sigma$ \\
\hline 754 & $\mathrm{mw}$ & $\pi$ & 1724 & vs & $\sigma(?)$ \\
\hline 768 & vvw & $\ldots$ & $1928\}$ & $\mathbf{w}$ & $\pi$ \\
\hline 781 & vw & $\sigma$ & $1918\}$ & $\mathrm{W}$ & $\pi$ \\
\hline 803 & vvw & - & $2060\}$ & $\mathrm{w}$ & $\pi$ \\
\hline 816 & $\mathrm{mw}$ & $\sigma$ & 2045 & w & $\pi$ \\
\hline 823 & $\mathrm{~m}$ & $\sigma$ & 2280 & $\mathrm{w}$ & - \\
\hline 814 & $\mathrm{mw}$ & $\pi$ & 2472 & $\mathrm{vw}$ & $\sigma$ \\
\hline 867 & $\mathrm{~ms}$ & $\pi$ & 2648 & vw & $\pi$ \\
\hline 898 & $\mathrm{vw}$ & - & 2800 & $\mathrm{vw}$ & $\pi(?)$ \\
\hline 967 & $\mathrm{~m}$ & $\pi$ & 2960 & $\mathrm{~m}$ & $\pi$ \\
\hline 1032 & $\mathrm{vw}$ & $\pi$ & 3320 & vw & $\pi$ \\
\hline 1068 & $\mathrm{vs}$ & $\pi$ & 3440 & $\mathrm{w}$ & $\sigma$ \\
\hline 1102 & vw & $\sigma$ & 3560 & $\mathrm{w}$ & $\pi(?)$ \\
\hline
\end{tabular}

listed the frequency, relative intensity, and polarization of the bands in the various deuterated polyethylene terephthalates.

\section{PREDICTED SPECTRUM OF POLYETHYLENE TEREPHTHALATE}

\section{Structure of Polyethylene Terephthalate}

A necessary preliminary to the assignment of bands in the infrared spectrum is a knowledge of the number and kinds of normal modes and their expected activity. This analysis must be based on a definite molecular structure, so we turn first to a consideration of the structure of polyethylene terephthalate.

As we noted earlier, the crystal structure of this polymer has been determined from an $x$-ray diffraction analysis ( 8 ). The molecules are thought to be centrosymmetric, and their arrangement in the triclinic cell of the crystal is shown in Fig. 5. The molecule is nearly planar and practically fully extended. Departures from planarity arise as a result of the $\mathrm{COO}$ group being about $12^{\circ}$ out of the plane of the benzene ring, and from a rotation of the $\mathrm{CH}_{2}-\mathrm{CH}_{2}$ hond (around the $\mathrm{O}-\mathrm{CH}_{2}$ bond as axis) of about $20^{\circ}$ from the planar configuration. From the 
TABLE IV

Infrared Spectrum of Polyethylene- $D_{4}$ Terephthalate- $-D_{4}$

\begin{tabular}{|c|c|c|c|c|c|}
\hline $\begin{array}{l}\text { Frequency, } \\
\mathrm{cm}^{-1}\end{array}$ & R. I. & Polarization & $\begin{array}{c}\text { Frequency } \\
\mathrm{cm}^{-1}\end{array}$ & R. I. & Polarization \\
\hline 317 & $\mathrm{~ms}$ & & 1277 & $\mathrm{~m}$ & - \\
\hline 365 & vw & & 1300 & $\mathrm{~m}$ & $\sigma$ \\
\hline 386 & w & $\pi$ & 1335 & s & $\pi$ \\
\hline 490 & $\mathrm{~m}$ & $\pi$ & 1340 & vw & - \\
\hline 502 & $\mathrm{~m}$ & $\pi$ & 1355 & $\mathrm{vw}$ & $\pi$ \\
\hline 615 & $\mathrm{w}$ & $\pi$ & 1416 & s & $\pi$ \\
\hline 640 & s & $\sigma$ & 1551 & $\mathrm{w}$ & $\pi$ \\
\hline 707 & $\mathrm{w}$ & $\sigma$ & 1586 & $\mathrm{w}$ & $\sigma$ \\
\hline 728 & $\mathrm{vw}$ & - & 1718 & vs & $\sigma(?)$ \\
\hline 754 & $\mathrm{mw}$ & $\pi$ & 1996 & $\mathrm{vw}$ & $\pi$ \\
\hline 763 & vVw & - & 2118 & $\mathrm{~m}$ & $\pi$ \\
\hline 804 & vvw & - & 2130 & vw & $\pi(?)$ \\
\hline 816 & $\mathrm{~m}$ & $\sigma$ & 2190 & $\mathrm{~m}$ & $\pi$ \\
\hline 823 & $\mathrm{~m}$ & $\sigma$ & 2247 & $\mathrm{mw}$ & $\sigma$ \\
\hline 844 & $\mathbf{m w}$ & $\pi$ & 2280 & vw & $\sigma$ \\
\hline 855 & $\mathrm{~m}$ & $\pi$ & 2340 & $\mathrm{vw}$ & $\pi$ \\
\hline 894 & VW & $\sigma$ & 2472 & $\mathrm{vw}$ & $\sigma$ \\
\hline 935 & $\mathrm{w}$ & $\sigma$ & 2648 & vw & $\pi$ \\
\hline 982 & $\mathrm{~m}$ & $\pi$ & 2800 & $\mathrm{vw}$ & $\pi$ \\
\hline 1030 & $\mathrm{w}$ & - & 2965 & $\mathrm{vW}$ & $\pi$ \\
\hline 1045 & $\mathrm{mw}$ & $\pi$ & 3100 & vw & $\pi(?)$ \\
\hline 1076 & vs & $\pi$ & 3320 & vw & $\pi$ \\
\hline 1112 & $\mathrm{~s}$ & $\sigma(?)$ & 3440 & $\mathrm{w}$ & $\sigma$ \\
\hline 1166 & $\mathrm{w}$ & $\pi(?)$ & 3560 & $\mathrm{w}$ & $\pi$ \\
\hline 1235 & vs & $\pi$ & & & \\
\hline
\end{tabular}

coordinates of the atoms it is possible to compute the orientation of various portions of the molecule with respect to the fiber axis. Some of these are given in Table V. The consistency between the spectrum and this structure, and the inferences from the spectrum concerning other possible struetures, will be considered later.

\section{Normal Modes Under the Factor Group}

On the basis of the structure of polyethylene terephthalate described above, the factor group (20), or unit cell group (21), of the space group $P 1$ is isomorphic to $C_{i}$. Because of the low symmetry of this group (the only element of symmetry being a center), the factor group analysis is not very helpful in interpreting the spectrum. It merely tells us that the mutual exclusion rule applies, and that therefore half of the normal modes of the molecule will be infrared active. In order to achieve an analysis of the spectrum we must therefore turn to a consideration of the local symmetries of portions of the molecule. This ap- 


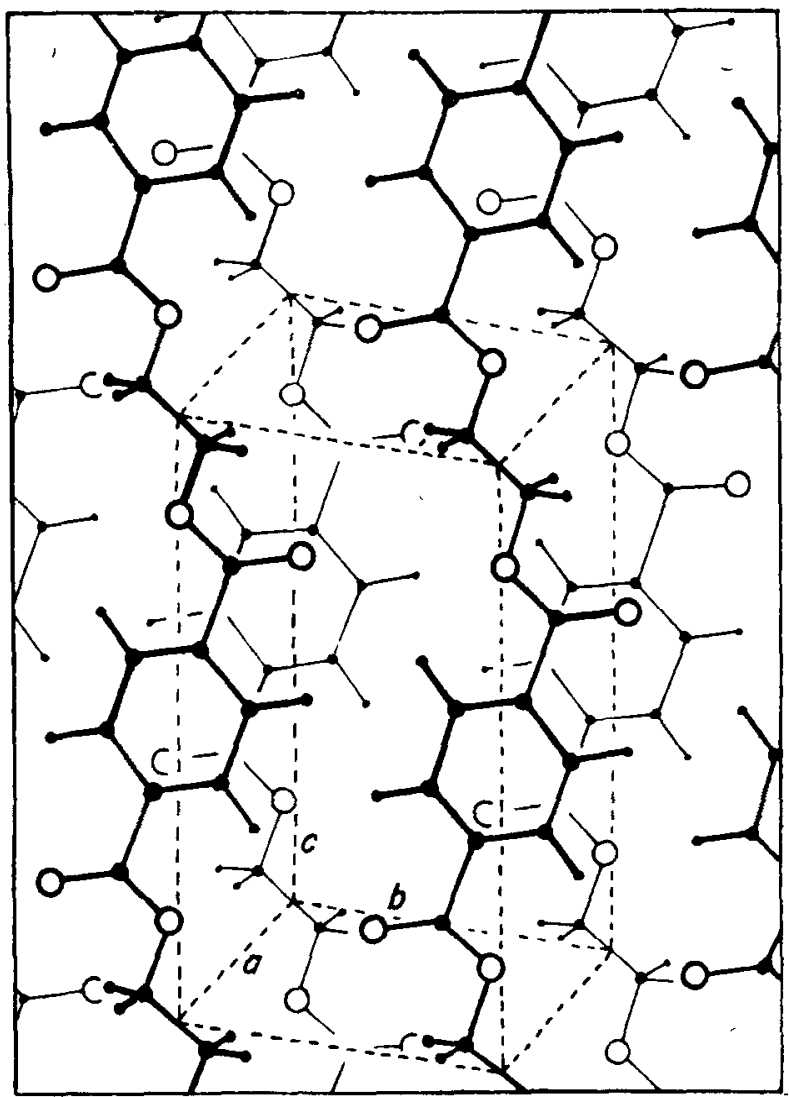

Fig. 5. Crystal structure of polyethylene terephthalate [after Daubeny et al. (8)].

TABLE $\mathrm{V}$

Orientation of Groups in Polyethylene Terephthalate Molecule with Respect to Fiber Axis ${ }^{\natural}$

Direction within group

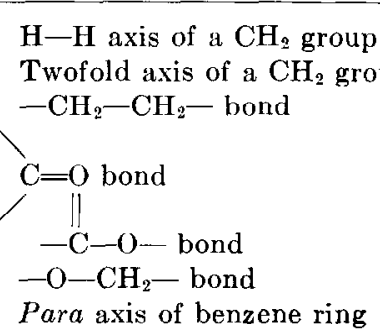

Angle with fiber axis

$77^{\circ}$
$71^{\circ}$
$57^{\circ}$
$76^{\circ}$
$47^{\circ}$
$19^{\circ}$
$24^{\circ}$

a Calculated from structure of Daubeny et al. (8). 
proximate method for treating the spectra of high polymers has been discussed (18) and satisfactorily applied (22). In the next paragraphs we will therefore consider the spectrum as determined by the following groups:<smiles>CC(=O)c1ccccc1</smiles>

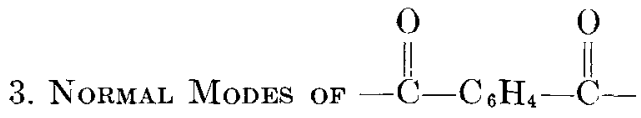

The modes of this group will be considered in terms of motions in which the $\mathrm{O}$ atoms move with respect to a rigid $\mathrm{C}-\mathrm{C}_{6} \mathrm{H}_{4}-\mathrm{C}$ framework, and those in which the $\mathrm{C}=\mathrm{O}$ group moves as a unit. The former modes contribute six normal vibrations, of which (if we assume a center of symmetry) three are infrared active. These involve essentially the stretching of the $\mathrm{C}=0$ bond, $\nu(\mathrm{C}=0)$, and the deformation modes in which the $\mathrm{O}$ moves parallel, $\gamma_{w}(\mathrm{C}=\mathrm{O})$, and perpendicular, $\gamma_{r}(\mathrm{C}=\mathrm{O})$, to the plane of the benzene ring. (We assume the $\mathrm{C}$ $\mathrm{C}_{6} \mathrm{H}_{4}-\mathrm{C}$ framework to be planar, even though the structure determination (8) indicates a slight departure from planarity.) Their polarizations in an oriented specimen are predicted (14) to be (see Table $V$ ) $\sigma, \pi$, and $\sigma$, respectively.

If we assume the presence of a center of symmetry, the $\mathrm{C}-\mathrm{C}_{6} \mathrm{H}_{4}-\mathrm{C}$ framework will have the symmetry $V_{h}$. We choose the axis through the para substituents as the $y$ axis and the axis perpendicular to the plane of the ring as the $z$-axis. The character table, including the number of normal modes under each species, $n_{t}$, and the polarization of the infrared active bands to be expected in an oriented specimen (see Table V), is shown in Table VI.

The normal modes of benzene have been computed in detail (23, 24), and those for para disubstituted benzenes have been estimated (25, 26$)$. On the

TABLE VI

Character Table for $\mathrm{C}-\mathrm{C}_{6} \mathrm{H}_{4}-\mathrm{C}$

\begin{tabular}{|c|c|c|c|c|c|c|c|c|c|c|c|c|}
\hline$V_{h}$ & $E$ & $C_{2}(z)$ & $C_{2}(y)$ & $C_{2}(x)$ & $i$ & $\sigma(x y)$ & $\sigma(x z)$ & $\sigma(y z)$ & $n_{t}$ & NULL & IR & $\mathrm{R}$ \\
\hline$A_{g}$ & 1 & 1 & 1 & 1 & 1 & 1 & 1 & 1 & 6 & & - & $p$ \\
\hline$B_{1 g}$ & 1 & 1 & -1 & -1 & 1 & 1 & -1 & -1 & 6 & $R_{z}$ & - & $d p$ \\
\hline$B_{\mathbf{2}_{g}}$ & 1 & -1 & 1 & -1 & 1 & -1 & 1 & -1 & 2 & $R_{y}$ & - & $d p$ \\
\hline$B_{3 g}$ & 1 & -1 & -1 & 1 & 1 & -1 & -1 & 1 & 4 & $R_{x}$ & - & $d p$ \\
\hline$A_{u}$ & 1 & 1 & 1 & 1 & -1 & -1 & -1 & -1 & 2 & & - & - \\
\hline$B_{1 u}$ & 1 & 1 & -1 & -1 & -1 & -1 & 1 & 1 & 4 & $T_{z}$ & $\sigma$ & - \\
\hline$B_{2 u}$ & 1 & -1 & 1 & -1 & -1 & 1 & -1 & 1 & 6 & $T_{y}$ & $\pi$ & - \\
\hline$B_{3 u}$ & 1 & -1 & -1 & 1 & -1 & 1 & 1 & -1 & 6 & $T_{x}$ & $\sigma$ & - \\
\hline
\end{tabular}



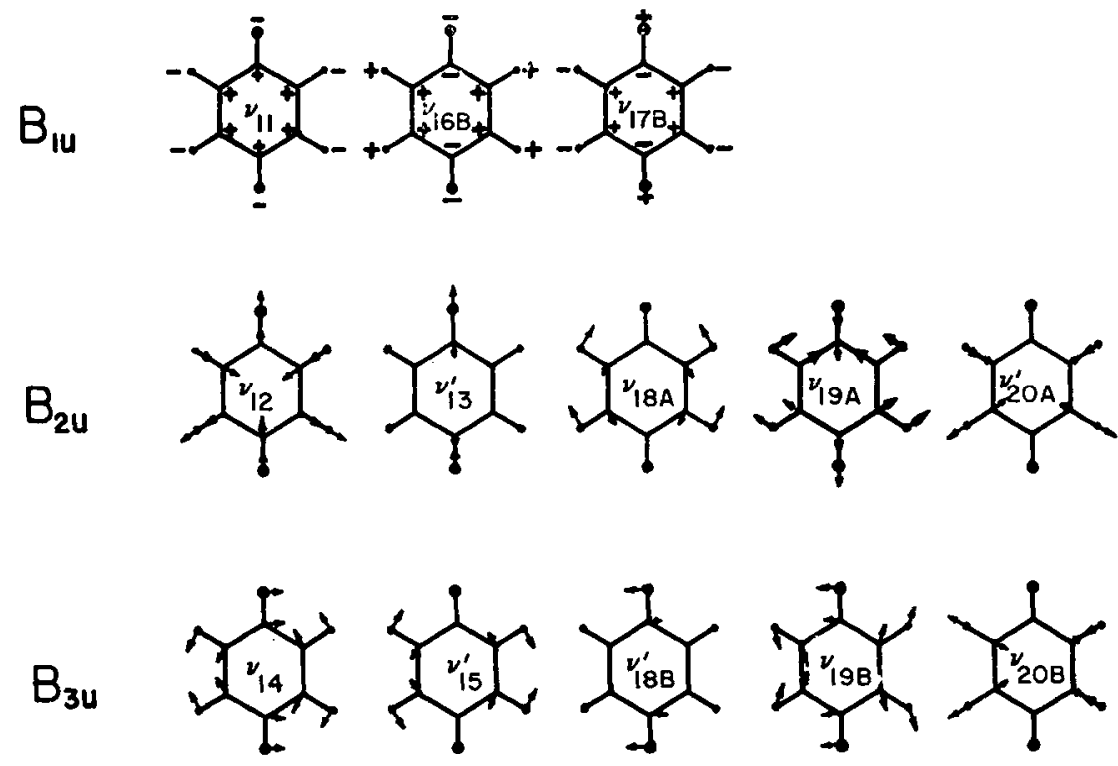

FIG. 6. Infrared active normal vibrations of para disubstituted benzene

basis of this work, we present in Fig. 6 a probable set of normal modes for the infrared active vibrations. The unprimed modes are benzene modes. The primed ones are modes derived from benzene modes, and represent reasonable combinations of the latter which are expected to approximate more nearly the actual normal vibrations. Although the mutual exclusion rule is expected to apply, it might be noted that the strict selection rules implied by Table VI may break down in the amorphous regions of the polymer, e.g., as a result of the two $\mathrm{C}=0$ groups no longer being strictly related by a center of symmetry. In this case, Raman active modes may appear weakly.

\section{Normal Modes of - $\mathrm{OCH}_{2} \mathrm{CH}_{2} \mathrm{O}-$}

In the above structure of polyethylene terephthalate $(8)$ the configuration of the $-\mathrm{OCH}_{2} \mathrm{CH}_{2} \mathrm{O}$ - portion of the chain is identical with that of a trans 1,2 disubstituted ethane of symmetry $C_{2 h}$. Symmetry considerations show that 9 infrared active modes are to be expected (27). From the form of the normal vibrations (28) we can determine the approximate nature and polarization (1/4) of the infrared active modes in an oriented specimen. Using the data of Table $V$, these are given in Table VII.

The above analysis is incomplete in that it predicts 12 null modes (translations and rotations) whereas we know that a long chain molecule has only four 
Approximate Nature and Polarizatiun of the Infraked Active Modes of Trans- $\mathrm{OCH}_{2} \mathrm{CH}_{2} \mathrm{O}-{ }^{*}$

\begin{tabular}{cc}
\hline Mode & Polarization \\
\hline$\nu_{a}\left(\mathrm{CH}_{2}\right)$ & $\sigma$ \\
$\nu_{s}\left(\mathrm{CH}_{2}\right)$ & $\sigma$ \\
$\delta\left(\mathrm{CH}_{2}\right)$ & $\sigma$ \\
$\gamma_{\mathrm{r}}\left(\mathrm{CH}_{2}\right)$ & $\sigma$ \\
$\gamma_{\mathrm{w}}\left(\mathrm{CH}_{2}\right)$ & $\pi$ \\
$\gamma_{t}\left(\mathrm{CH}_{2}\right)$ & - \\
$\nu(\mathrm{O}-\mathrm{C})$ & $\pi$ \\
Chain bending: in plane & $\sigma$ \\
Chain bending: out of plane & $\sigma$ \\
\hline
\end{tabular}

a Based on structure of Daubeny et al. (8).

$(17,18)$. It will be readily seen that when we consider the motions of the<smiles>CCOCCCCC(C)=O</smiles>

groups with respect to each other, 8 of the above 12 modes are internal skeletal motions. Among these are modes such as the stretching of the $-\mathrm{C}-\mathrm{O}$ bond, $\nu(\stackrel{\|}{\mathrm{C}}-\mathrm{O})$, and the deformations of the $\mathrm{CCO}$ and $\mathrm{COC}$ angles, $\delta(\mathrm{CCO})$ and $\delta(\mathrm{COC})$; the others are chain bending modes. We will consider these later.

In the following paragraphs we will discuss first the assignment of the benzene ring vibrations, showing that a consistent analysis is possible on the basis of the orientation of the ring in the proposed crystal structure. We will then consider the assignments of the $\mathrm{C}=\mathrm{O}$ group. Finally, we will discuss the assignments for the $-\mathrm{OCH}_{2} \mathrm{CH}_{2} \mathrm{O}-$ portion of the molecule. It will be shown that for the latter case the spectrum is not consistent with the proposed structure, and an alternative structure will be suggested. The question of the suggested $(9,10)$ gauche configuration of the $-\mathrm{OCH}_{2} \mathrm{CH}_{2} \mathrm{O}-$ group will be considered at that time.

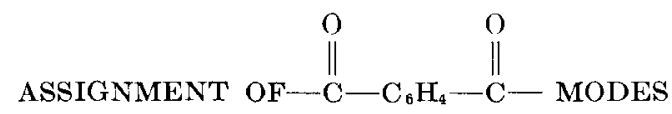

In assigning the substituted benzene ring modes we shall be guided by several principles. To begin with, we start with the assignments which have been worked out in detail for benzene (24, 29) and para dideuterobenzene (24-26). As will be shown below, modes in which the substituents do not move have frequencies very close to those in benzene. In some cases use can be made of calculations 
(30-32) of the effect of the substituent on the other modes. The deuteration results are of help in identifying some of the modes, as are pertinent correlations from smaller analogous molecules (33). We also utilize the polarization measurements in making assignments, seeing no clear-cut reason why they should be held in question (15). In fact it seems that a set of assignments consistent with the polarization measurements can be achieved for the benzene ring modes, which gives confidence that the polarization results are also applicable to the other modes. Finally, it must not be overlooked that relaxation of the $V_{h}$ symmetry, such as could occur in the amorphous regions, will result in the appearance of some of the normally infrared inactive Raman modes.

\section{Assignment of $\mathrm{B}_{2 u}$ Modes}

We consider first the assignment of the $B_{2 u}$ modes, since they should be readily identifiable by their $\pi$ polarization. The five $B_{2 u}$ modes derive from two inactive $B_{1 u}$ modes $\left(\nu_{12}\right.$ and $\left.\nu_{13}\right)$ and three infrared active $E_{1 u}$ modes $\left(\nu_{18}, \nu_{19}\right.$, and $\left.\nu_{20}\right)$ of benzene.

The $\nu_{18 A}$ mode should be readily identified since the substituents in the para position do not move. It occurs as a strong band at $1037 \mathrm{~cm}^{-1}$ in benzene, and we have no difficulty in assigning to it the strong $\pi$ band at $1020 \mathrm{~cm}^{-1}$ in the polymer. It probably shifts to about $860 \mathrm{~cm}^{-1}$ on ring deuteration, in comparison with the shift to $819 \mathrm{~cm}^{-1}$ in $2,3,5,6$-tetradeuterobenzene (26). The CH stretching mode, $\nu_{204}^{\prime}$, can similarly be identified with the $\pi$ band at $3055 \mathrm{~cm}^{-1}$. It is found at $3060 \mathrm{~cm}^{-1}$ in paradideuterobenzene (26). The $\nu_{104}$ mode occurs at 1485 $\mathrm{cm}^{-1}$ in benzene, and the evidence seems to indicate $(23,33,34)$ that it moves to slightly higher frequencies in para disubstituted benzenes. On this basis the $\nu_{19 \mathrm{~A}}$ mode can be readily assigned to the $\pi$ band at $1504 \mathrm{~cm}^{-1}$. From its disappearance on ring deuteration, and the relative enhancement and slight shift of the band near $1410 \mathrm{~cm}^{-1}$, deuteration appears to shift it to about $1415 \mathrm{~cm}^{-1}$. This indicates that this mode contains a significant proportion of $\mathrm{H}$ motion, perhaps as shown in Fig. 6.

The identification of the $\nu_{12}$ and $\nu_{13}^{\prime}$ modes is less certain. The latter, as indicated, is expected (26) to be a stretching mode of the $\mathrm{CC}$ bond between the benzene ring and the $\mathrm{C}=\mathrm{O}$ group. Because of the planarity of the

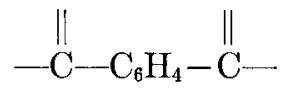

framework, and the resulting resonance in this conjugated structure, we expect this $\mathrm{CC}$ bond to have some double-bond character. This should place the $\nu_{13}^{\prime}$ mode at a higher value than if a pure CC single bond were involved (for example, in butadiene the $\nu(\mathrm{CC})$ mode is found (35) at $1205 \mathrm{~cm}^{-1}$ ). We believe that $\nu_{13}^{\prime}$ should be assigned to either of the bands at 1343 or $1410 \mathrm{~cm}^{-1}$. Since we 
will show later that the $1410 \mathrm{~cm}^{-1}$ band is most probably a combination band, we choose the band at $1343 \mathrm{~cm}^{-1}$. For various reasons this band cannot be assigned to a $\mathrm{CH}_{2}$ mode, such as has been suggested or implied by many authors $(4,9,10,15,19)$. At present we will just note that this band is not shifted by deuteration of the $\mathrm{CH}_{2}$ group (see Fig. 4). It may seem from Fig. 2 that denteration has caused this band to disappear, but as we shall presently discuss, there is good reason to believe that it has merged with the band at $1263 \mathrm{~cm}^{-1}$, which, in polyethylene- $D_{4}$ terephthalate (Fig. 2) has broadened and shifted to 1275 $\mathrm{cm}^{-1}$, the highest value it assumes in the four polymers. The absence of a shift on ring deuteration is quite consistent with the nature of this mode.

Before proceeding with the other assignments, it is necessary to say a few words about the significant increase in intensity of the $1343-\mathrm{cm}^{-1}$ band which we have noted occurs upon crystallization of the polymer. This behavior is quite consistent with the proposed assignment. If, as we shall show later, the polymer in the amorphous regions is characterized by a loss of its center of symmetry (as evidenced by the appearance of Raman active bands), we would expect this to imply a departure from planarity of the $-\mathrm{C}-\mathrm{C}_{6} \mathrm{H}_{4}-\mathrm{C}-$ group. This in turn will be associated with a loss of resonance in the CC bond whose stretching is involved in the $\nu_{13}$ mode, and the position and intensity of this mode would be expected to change. The increased intensity upon crystallization is then just a reflection of the increased number of $-\stackrel{\mathrm{C}}{-}-\mathrm{C}_{6} \mathrm{H}_{4}-\stackrel{\mathrm{C}}{\mathrm{C}}-$ groups with strict $V_{h}$ symmetry. If this effect occurs for the $\nu_{13}^{\prime}$ mode, we shall expect it in other modes, especially those in which the motions significantly involve this $\mathrm{CC}$ bond, and this in fact seems to be the case. It might be noted that the suggested merging of this band with that at $1263 \mathrm{~cm}^{-1}$ in polyethylene- $D_{4}$ terephthalate is not at all unreasonable. We will see that the latter band is to be associated with $\nu(\mathrm{C}-\mathrm{O})$, and it is quite likely that under certain conditions $\nu(\mathrm{C}-\mathrm{O})$ and $\nu_{13}^{\prime}$ could be quite close to each other.

The final mode in the $B_{2 u}$ species, $\nu_{12}$, is an inactive mode in benzene located at about $1010 \mathrm{~cm}^{-1}$. Its assignment in polyethylene terephthalate is difficult to make with certainty, but we believe that the position, intensity, polarization, deuteration behavior, and intensity increase upon crystallization of the band at $973 \mathrm{~cm}^{-1}$ are consistent with its assignment to $\nu_{12}$.

\section{Assignment of $B_{1 u}$ Modes}

The three $B_{1 u}$ modes derive from one infrared active $A_{u}$ mode $\left(\nu_{11}\right)$ and two inactive $E_{26}$ modes $\left(\nu_{16}\right.$ and $\left.\nu_{17}\right)$ of benzene. The $\nu_{16 B}$ mode is found at $405 \mathrm{~cm}^{-1}$ in benzene, and is expected in the same general region (23,36) in para disub- 
stituted benzenes. Since it should exhibit $\sigma$ polarization in oriented polyethylene terephthalate, the only possibilities for assignment are bands at 355 and 430 $\mathrm{cm}^{-1}$. The former is more reasonably assigned otherwise. Choice of the latter will be shown to be consistent with certain expected combinations. We therefore assign the band at $430 \mathrm{~cm}^{-1}$ to $\nu_{16 B}$.

The two out-of-plane bending modes will be expected to give rise to moderately strong $\sigma$ bands in the region of approximately $600-900 \mathrm{~cm}^{-1}(24,32,33$, 37). Despite its early misassignment $(4)$, it soon became evident $(13,15)$ that the band at $730 \mathrm{~cm}^{-1}$ is to be associated with one of these modes. Tilting experiments on oriented specimens (13) also showed that the $875 \mathrm{~cm}^{-1}$ band is associated with an out-of-plane bending mode. Ring deuteration (19) confirms this assignment. From the deuterated spectra (see Figs. 1 and 3) it is clear that the $730-\mathrm{cm}^{-1}$ band shifts to $640 \mathrm{~cm}^{-1}$, and the $875-\mathrm{cm}^{-1}$ band shifts to near $820 \mathrm{~cm}^{-1}$ (an assignment of the shift to $707 \mathrm{~cm}^{-1}$ leaves the moderately strong $\sigma$ bands near $820 \mathrm{~cm}^{-1}$ completely unassignable). On the basis of the larger isotope shift and greater intensity of the $730-\mathrm{cm}^{-1}$ band we assign it to $\nu_{11}$, whereas $\nu_{17 B}$ is associated with the band at $875 \mathrm{~cm}^{-1}$.

\section{Assignment of $B_{3 u}$ Modes}

The five $B_{3 u}$ modes derive from two inactive $B_{2 u}$ modes $\left(\nu_{14}\right.$ and $\left.\nu_{15}\right)$ and three infrared active $E_{1 u}$ modes $\left(\nu_{18}, \nu_{19}\right.$, and $\left.\nu_{20}\right)$ of benzene. The $\nu_{20 B}$ mode, which is found in benzene at $3080 \mathrm{~cm}^{-1}$ and is expected to change hardly at all in para disubstituted benzenes, is readily identified by its position and polarization with the band at $3082 \mathrm{~cm}^{-1}$. The $\nu_{19 B}$ mode should be located near $1450 \mathrm{~cm}^{-1}$, but is often not found (33). We believe that it may be associated with the weak crystallization-variable band at $1473 \mathrm{~cm}^{-1}$. It is the only band with appropriate polarization in the expected region, and its enhancement with increasing crystallinity is consistent with the arguments set forth above in connection with the assignment of $\nu_{13}^{\prime}\left(B_{2 u}\right)$. (A possible assignment to a $\delta\left(\mathrm{CH}_{2}\right)$ mode will be considered later.)

The assignments of two of the other three modes can be made with fair certainty. On the basis of analogy with $p$-xylene (23), where the band is thought to be located at $232 \mathrm{~cm}^{-1}$, we would assign the $\nu_{18 B}^{\prime}$ mode in the polymer to the weak band at $250 \mathrm{~cm}^{-1}$. The $\nu_{15}^{\prime}$ mode should be essentially a hydrogen mode (26), and should be found near $1100 \mathrm{~cm}^{-1}(23,26)$. From the appearance of $\pi$ bands in this region in polyethylene terephthalate it would seem that no assignment can be made. However, it has already been noted (10) that this group of bands is of quite complex origin. In fact weak bands near this position are found in terephthalic acid (11), which would not be expected to exhibil the $\nu(\mathrm{O}-\mathrm{C})$ mode which is the main contributor to this region in the higher oligomers (where the intensity relative to the very strong $\nu(\mathrm{C}-\mathrm{O})$ mode near $1250 \mathrm{~cm}^{-1}$ remains 
essentially constant) and in polyethylene terephthalate. We therefore fecl that there is good reason to believe that $\nu_{15}^{\prime}$ contributes to the band at $1100 \mathrm{~cm}^{-1}$. Because of its weakness, its $\sigma$ polarization is not evident; the $\pi$ polarization of the overlapping band dominates. This assignment is further supported by the presence of a weak $\sigma$ band at $935 \mathrm{~cm}^{-1}$ in the ring deuterated polymer (see Fig. 4) which bears the same isotopic shift ratio to the $1100-\mathrm{cm}^{-1}$ band as is the case for the analogous $\mathrm{CH}$ bending mode $\nu_{18 \mathrm{~A}}$. The assignment of the remaining mode of this species, $\nu_{14}$, is in doubt in benzene (24), and we have been unable to locate it with any assurance in our polymer spectrum.

\section{Assignment of Raman Active Modes}

The assignments discussed in the above paragraphs still leave many bands, which are not associated with $\mathrm{C}=\mathrm{O},-\mathrm{OCH}_{2} \mathrm{CH}_{2} \mathrm{O}-$, or skeletal modes, unaccounted for. We will show in this and the next section that these bands are due to Raman active modes which become infrared active as a result of loss of symmetry, and to combination bands.

As we have observed before, loss of the center of symmetry, e.g., by rotations of the $\mathrm{C}=\mathrm{O}$ groups out of the plane of the benzene ring, will lead to the appearance in the spectrum of bands which are forbidden under $V_{h}$ symmetry. It should be possible to identify such bands by three characteristics: knowledge of their positions from Raman data, the fact that their intensity increases with increase in amorphous content, and their polarization, which should be correlatable with the activity predicted under a lower symmetry, which would most probably be $C_{2 v}$ (22). For example, relaxation of symmetry should give rise (33) to the appearance of bands associated with $\nu_{8}$, which appears at $1585 \mathrm{~cm}^{-1}$ in benzene. The evidence strongly suggests that the bands at 1580 and $1617 \mathrm{~cm}^{-1}$, which increase in intensity with increasing amorphous content, are due to the $\nu_{8 A}\left(A_{1}\right)$ and $\nu_{8 B}\left(B_{1}\right)$ modes, respectively. (For the form of these normal modes, see Refs. 22 or 23.) These modes are actually strongly mixed with $\nu_{9}(24)$, which accounts for the small shift to 1551 and $1586 \mathrm{~cm}^{-1}$, respectively on ring deuteration. Other modes which seem to fit into this category $(39)$ are $\nu_{9 A}\left(A_{1}\right)$ at $1172 \mathrm{~cm}^{-1}, \nu_{4}\left(B_{2}\right)$ at $680 \mathrm{~cm}^{-1}, \nu_{6 B}\left(B_{1}\right)$ at $613 \mathrm{~cm}^{-1}$, and possibly $\nu_{6 A}\left(A_{1}\right)$ at $525 \mathrm{~cm}^{-1}$. Other, less certain, possibilities are $\nu_{2}^{\prime}$ at $1370 \mathrm{~cm}^{-1}$ [this is the Raman active counterpart of $\nu_{13}^{\prime}$, and is found at a slightly higher frequency than the infrared active mode in para dideuterobenzene $(25,26)] ; \nu(\mathrm{CC})$, the stretching of the $\mathrm{H}_{2} \mathrm{C}-\mathrm{CH}_{2}$ bond, at $1043 \mathrm{~cm}^{-1}$; and $\nu_{10 B}\left(B_{3 g}\right)$ at $145 \mathrm{~cm}^{-1}$. The reason for suggesting the latter assignment is that $\nu_{10 B}$ is expected to occur at a low frequency (23), and its assignment as suggested leads to the accurate reproduction of a combination band observed in benzene (29).

\section{Assignment of Combination Bands}

It is known that in benzene (29) and in substituted benzenes (38) certain characteristic combination bands of the out-of-plane $\mathrm{CH}$ bending vibrations 
appear with significant intensity in the infrared spectrum. This was found to be true in polystyrene (22), and we would expect a similar situation in the spectrum of polyethylene terephthalate. This will be shown to be the case, which also aids in confirming some of the assignments of the fundamentals.

In assigning combination bands, we are guided by two principles. The species of the combination should follow from those of its components according to the character table, and Raman active components should have frequencies near those of the corresponding mode in benzene when this mode is one in which there is no motion of the para substituents. In the latter connection it is also often possible to make use of Raman data on similar smaller molecules, such as dimethyl and diethyl terephthalate (39).

In this way, for example, we can identify two characteristic combination bands at 1830 and $1955 \mathrm{~cm}^{-1}$. The former is a $\pi$ band and therefore belongs to the $B_{2 u}$ species. One of the characteristic combinations is $\nu_{10}+\nu_{17}$, and it will be readily seen that $\nu_{10 A}+\nu_{17 A}(849+984=1833$ in benzene $)$ gives a band in the appropriate region and of the correct species. If we use the value of $85.3 \mathrm{~cm}^{-1}$ for $\nu_{10 \mathrm{~A}}$ from diethyl terephthalate (39), this would place $\nu_{17 \mathrm{~A}}$ at about $977 \mathrm{~cm}^{-1}$. The $\sigma$ band at $1955 \mathrm{~cm}^{-1}$ must belong to the $B_{1 u}$ or $B_{3 u}$ species. Again it can be seen that the characteristic combination $\nu_{17 A}+\nu_{5}$ gives a band (on the basis of the benzene frequencies) which is in the appropriate range and of the correct species. Using the above value for $\nu_{17 A}$ we find that $\nu_{5}$ is at about $978 \mathrm{~cm}^{-1}$, not far from its value of $967 \mathrm{~cm}^{-1}$ in para dideuterobenzene (25). Using this value for $\nu_{5}$ and our assigned value for $\nu_{16 B}$ we find that another characteristic combination, $\nu_{5}+\nu_{16 B}$, is accurately reproduced. It might be thought that the $1410-\mathrm{cm}^{-1}$ band is too strong to be attributed to a combination band, but in fact such combinations are quite strong in benzene (29). Finally, $\nu_{5}+\nu_{16 \mathrm{~A}}$ may be contributing to the $1370-\mathrm{cm}^{-1}$ band. The other possible combinations of these characteristic out-of-plane $\mathrm{CH}$ bending modes give bands which, other than the apparently absent $\nu_{5}+\nu_{17 B}$, overlap with other strong bands in the spectrum.

In summary, it appears that the spectrum predicted for the $\mathrm{C}-\mathrm{C}_{6} \mathrm{H}_{4}-\mathrm{C}$ framework is satisfactorily identifiable in detail within the spectrum of polyethylene terephthalate. Since this has been based on the assumption of an orientation of the benzene ring similar to that in the crystal structure, we may presume that this orientation (viz., with the para axis of the substituted ring oriented essentially parallel to the stretching direction) is substantiated by the spectral results. We have also seen that the intensity of certain of the ring modes is sensitive to the exact symmetry of the ring, which seems reasonably to be associated with the amorphous or crystalline state of the polymer.

In the category of modes associated with the $\mathrm{C}=\mathrm{O}$ group we expect to find three bands, and their identification is not too difficult. There is no question about the location of $\nu(\mathrm{C}=\mathrm{O})$ at $1724 \mathrm{~cm}^{-1}$. The $\gamma_{\mathrm{r}}(\mathrm{C}=\mathrm{O})$ mode is expected to give rise to a $\sigma$ band. On the basis of its assignment in ketones to a band at 
$390 \mathrm{~cm}^{-1}(40)$, we feel that it is probably to be assigned to the $355-\mathrm{cm}^{-1} \sigma$ band in polyethylene terephthalate. The $\gamma_{w}(\mathrm{C}=0)$ mode is assigned to a band at $639 \mathrm{~cm}^{-1}$ in $\mathrm{CH}_{3} \mathrm{COOCH}_{3}(41)$ and at $527 \mathrm{~cm}^{-1}$ in $\mathrm{CH}_{3} \mathrm{COCH}_{2} \mathrm{COCH}_{3}(40)$. The assignment in the polymer is not entirely unambiguous, but we believe this mode can reasonably be assigned to the $\pi$ band at $502 \mathrm{~cm}^{-1}$. Its supposed enhancement in the amorphous state (15) may be related to the interaction between the $\mathrm{C}=\mathrm{O}$ group and the benzene ring, which we discussed earlier.

\section{ASSIGNMENT OF $-\mathrm{OCH}_{2} \mathrm{CH}_{2} \mathrm{O}-\mathrm{AND}$ SKELETAL MODES}

In discussing these assignments, we will first try to dispose of those modes involving stretching and deformation vibrations of the $-\mathrm{C}-\mathrm{O}-\mathrm{C}-$ group, reserving for the subsequent discussion the assignment of the $\mathrm{CH}_{2}$ modes and the attendant questions of the configuration of the $-\mathrm{OCH}_{2} \mathrm{CH}_{2} \mathrm{O}-$ portion of the chain.

1. Assignment of $-\stackrel{\mathrm{C}}{\|}-\mathrm{O}-\mathrm{C}-$ Modes

Esters are known $(41,42)$ to give rise to two strong absorption bands associated with the stretching of the $\mathrm{C}-\mathrm{O}$ and $\mathrm{O}-\mathrm{C}$ bonds. These can be assigned with a fair degree of certainty to the strong $\pi$ bands at 1263 and $1120 \mathrm{~cm}^{-1}$, respectively. The smaller dichroism of the former is consistent with the less parallel orientation of the $\stackrel{\mathrm{C}}{-}-\mathrm{O}$ bond (see Table $\mathrm{V}$ ). The presence of two $\pi$ bands in the $1100-\mathrm{cm}^{-1}$ region may be an indication of the dependence of the $\nu(\mathrm{O}-\mathrm{C})$ mode on the configuration of the neighboring $\mathrm{CH}_{2}$ groups with respect to the $\mathrm{C}_{6} \mathrm{H}_{4}-\mathrm{C}-$ - portion of the chain. 'This is hypothetical at present, but we will shortly consider some arguments which point in this direction.

Assignments have been suggested (41) for the $\delta(\mathrm{CCO})$ and $\delta(\mathrm{COC})$ modes. These are consistent with the bands which we find in the $300-500 \mathrm{~cm}^{-1}$ region. The difficulty about making a reasonably certain assignment is that we do not know the forms of the normal vibration. It would seem, on the basis of a simple three mass model, that these deformation vibrations should exhibit $\sigma$ polarization. However, it is well known (49) that the actual form of this vibration is a sensitive function of the masses, and in fact for certain mass distributions this mode will exhibit $\pi$ polarization (Ref. 28, pp. 225-227). We will therefore assume that this is the case, and base our assignments on those for $\mathrm{CH}_{3} \mathrm{COOCH}_{3}(41)$. This leads to the assignment of the $437-\mathrm{cm}^{-1}$ band to $\delta(\mathrm{CCO})$ and the $383-\mathrm{cm}^{-1}$ band to $\delta(\mathrm{COC})$. Perhaps the apparent weakening of the $437-\mathrm{cm}^{-1}$ band on ring 
deuteration is associated with an interaction between this mode and one of the ring modes. We are unable to indentify with any certainty the skeletal modes, and suggest that they may be the origin of perhaps one of the weak low-frequency bands in the spectrum. Several combination bands involving these $\mathrm{C}-\mathrm{O}-\mathrm{C}$ modes seem to occur in the spectrum, and are indicated in Table I.

\section{Assignment of $\mathrm{CH}_{2}$ Modes}

The assignments of the $\nu_{s}\left(\mathrm{CH}_{2}\right)$ and $\nu_{a}\left(\mathrm{CH}_{2}\right)$ modes can be made on the basis of their well-established positions in hydrocarbons (44), where they are found at 2853 and $2925 \mathrm{~cm}^{-1}$, respectively. If we take into account the increase in these frequencies which occurs when the $\mathrm{CH}_{2}$ group is adjacent to the ester linkage $(45)$, then there is no difficulty in assigning $\nu_{8}\left(\mathrm{CH}_{2}\right)$ and $\nu_{a}\left(\mathrm{CH}_{2}\right)$ to bands at 2908 and $2970 \mathrm{~cm}^{-1}$, respectively. What becomes immediately apparent is that their $\pi$ polarization is inconsistent with the $\sigma$ polarization predicted from the crystal structure $(8,14)$ (see Table $\mathrm{V}$ ). We shall return to this point presently. There may be an additional $\sigma$ band in this group, since a third $\sigma$ band appears in $\mathrm{CD}_{2}$ polymers (see Figs. 2 and 4 ). The $\delta\left(\mathrm{CH}_{2}\right)$ mode is similarly (44) located with no difficulty at $1455 \mathrm{~cm}^{-1}$, shifting to $1076 \mathrm{~cm}^{-1}$ on deuteration. Its $\pi$ polarization is consistent (14) with that of the $\nu_{s}\left(\mathrm{CH}_{2}\right)$ mode. The possible presence of a $\sigma \nu\left(\mathrm{CH}_{2}\right)$ mode suggests that the $\sigma$ band at $1473 \mathrm{~cm}^{-1}$ may be a $\delta\left(\mathrm{CH}_{2}\right)$ mode. This is difficult to verify by deuteration because of the weakness of the band.

The assignment of the $\gamma_{\mathrm{w}}\left(\mathrm{CH}_{2}\right)$ mode is of especial importance, since it has been made the basis of a postulated gauche configuration for the $-\mathrm{OCH}_{2} \mathrm{CH}_{2} \mathrm{O}$ group in the amorphous regions $(9,10,19)$. On the basis of the existence of similar bands in the spectra of rotational isomers of ethylene dihalides (46) and in polyethylene glycol $\left(4^{7}\right)$, Ward $(9,10)$ has postulated that the 1343- and 1370$\mathrm{cm}^{-1}$ bands are associated with $\gamma_{\mathrm{w}}\left(\mathrm{CH}_{2}\right)$ modes of the trans and gauche forms of the $-\mathrm{OCH}_{2} \mathrm{CH}_{2} \mathrm{O}$ - group, respectively. We wish to point out that these bands are probably not due to $\mathrm{CH}_{2}$ groups. First, as we have already noted, the 1343$\mathrm{cm}^{-1}$ band does not shift on deuteration of the $\mathrm{CH}_{2}$ groups. The spectra indicate that the same is true of the $1370-\mathrm{cm}^{-1}$ band. Seennd, the $\gamma_{w}\left(\mathrm{CH}_{2}\right)$ mode, which is located at about $1369 \mathrm{~cm}^{-1}$ in hydrocarbons (44), is generally very weak in polymers in comparison to the $\delta\left(\mathrm{CH}_{2}\right)$ mode $(22,44,48-50)$. Although in some cases its intensity appears to be enhanced (51), it is never more intense than the $\delta\left(\mathrm{CH}_{2}\right)$ mode. On this basis it would be difficult to assign the $1343-\mathrm{cm}^{-1}$ band to $\gamma_{\mathrm{w}}\left(\mathrm{CH}_{2}\right)$. Third, as we have shown (14), in terms of the strong $\pi \nu_{8}\left(\mathrm{CH}_{2}\right)$ and $\nu_{\mathrm{a}}\left(\mathrm{CH}_{2}\right)$ modes the $\gamma_{\mathrm{w}}\left(\mathrm{CH}_{2}\right)$ mode should exhibit $\sigma$ polarization. This also eliminates the $134: 3-\mathrm{cm}^{-1}$ band from consideration, leaving only the $1370-\mathrm{cm}^{-1}$ band. The latter may be due to $\gamma_{w}\left(\mathrm{CH}_{2}\right)$, but at present we think this unlikely, 
considering that it does not shift on deuteration of the $\mathrm{CH}_{2}$ group. We would therefore conclude that $\gamma_{w}\left(\mathrm{CH}_{2}\right)$ is not detected in the spectrum, and would ar:count for the intensity changes of the $1343-\mathrm{cm}^{-1}$ band not by rotational isomerism of the $\mathrm{CH}_{2}$ groups but, as indicated in the earlier discussion, by the influence of resonance in the $-\stackrel{\mathrm{C}}{\mathrm{C}}-\mathrm{C}_{6} \mathrm{H}_{4}-\stackrel{\mathrm{C}}{\mathrm{C}}-$ group on certain of the benzene ring modes.

On the basis of the crystal structure of polyethylene terephthalate $(8)$ the $\gamma_{\mathbf{r}}\left(\mathrm{CH}_{2}\right)$ mode should give rise to a $\sigma$ band. There is no band in the spectrum in the appropriate region which can thus be assigned. If, however, we follow the observed $\pi$ polarization of the intense $\nu_{\mathrm{s}}\left(\mathrm{CH}_{2}\right)$ and $\nu_{\mathrm{a}}\left(\mathrm{CH}_{2}\right)$ modes in expecting (1.4) a $\pi \gamma_{\mathrm{r}}\left(\mathrm{CH}_{2}\right)$ mode, then the assignment of this mode to the $\pi$ band at 845 $\mathrm{cm}^{-1}$ is a reasonable one, particularly since this band appears to shift on deuteration of the $\mathrm{CH}_{2}$ group. The only other $\mathrm{CH}_{2}$ mode, $\gamma_{\mathrm{t}}\left(\mathrm{CH}_{2}\right)$, the $\mathrm{CH}_{2}$ twisting mode, is generally too weak to be observed, and we have not been able to assign it in the present work.

\section{STRUCTURE OF POLYETHYLENE TEREPHTHALATE}

We wish to consider now the implications of the above results with respect to the structures that have been suggested for the crystalline $(8)$ and amorphous $(9,10)$ forms of polyethylene terephthalate.

It has already been noted that, whereas the spectrum is consistent with the benzene ring orientation proposed for the crystalline structure, this is not the case for the $\mathrm{CH}_{2}$ groups. Their modes exhibit dichroism in complete disagreement with that predicted, and, if the assignment of the $84 \tilde{5}-\mathrm{cm}^{-1}$ erystalline band to $\gamma_{\mathrm{r}}\left(\mathrm{CH}_{2}\right)$ is correct, this dichroism seems to be associated with the crystalline phase. Since we find no reason to hold the polarization data in question, nor their correlation with the transition moments of the $\mathrm{CH}_{2}$ group, we are led to suggest that the proposed chain structure may be in error with respect to the orientation of the $\mathrm{CH}_{2}$ groups. It is interesting to note that the authors themselves $(8)$ point out that the location of these carbon atoms was the least reliable part of the structure determination. The dichroism of the $\mathrm{CH}_{2}$ modes can be accounted for by a change in the structure which, molecular models indicate, is easily possible. This consists of an additional rotation of the $\mathrm{CH}_{2} \mathrm{CH}_{2}$ bond about the $\mathrm{O}-\mathrm{CH}_{2}$ bond followed by a rotation about the $\mathrm{C}-\mathrm{O}$ bond. This still preserves the center of symmetry and gives a fiber axis repeat essentially identical with that observed. It should be noted that such a larger rotation about the $\mathrm{O}-\mathrm{CH}_{2}$ bond is observed in polyethylene adipate $(8,52)$, a fact which indicates that rotation about this bond occurs with relative ease. We feel that the interpretation of the infrared spectrum is compelling enough so that the possibility of the predominant structure being such as that suggested here must be seriously considered. 
The second point concerns the presence of a gauche configuration for the $-\mathrm{OCH}_{2} \mathrm{CH}_{2} \mathrm{O}-$ group in the amorphous regions. As will have been gathered by now, the changes in the spectrum upon which the above conclusion is based are not associated with $\mathrm{CH}_{2}$ modes, as claimed $(9,10,53)$. Such prominently erystallization sensitive bands as those at 973 and $1343 \mathrm{~cm}^{-1}$ are not $\mathrm{CH}_{2}$ modes, since they are not affected by deuteration in the expected manner. While it is possible that the chains in the amorphous regions have gauche $-\mathrm{OCH}_{2} \mathrm{CH}_{2} \mathrm{O}-$ groups, we do not think that unambiguous evidence exists in the infrared spectrum in support of this. Rather we believe that the changes that occur upon crystallization are associated with changes in the symmetry and resonance characteristics of the $-C-\mathrm{C}_{6} \mathrm{H}_{4}-\mathrm{C}-$ framework. In addition, in view of the discussion of the previous paragraph, it is probably more likely that structural changes in the chains in the amorphous regions are associated with rotations around the $\mathrm{O}-\mathrm{CH}_{2}$ bonds than with discrete rotationally isomeric states about the $\mathrm{CH}_{2}-\mathrm{CH}_{2}$ bond.

\section{ACKNOWLEDgments}

The authors wish to express their appreciation to E. I. du Pont de Nemours and Company for supporting grants, during the tenure of which part of this work was done. We are also indebted to this company for making available to us samples of deuterated polyethylene terephthalate. We wish to thank 1)rs. W. W. Daniels and R. E. Kitson for the opportunity of reading the manuscript of their paper prior to publication, and Dr. H. W. Wyckoff for helpful discussions on the molecular model of polyethylene terephthalate. We are grateful to Dr. G. B. B. M. Sutherland for helpful discussions.

REceIved: October 7, 1958

\section{REFERENCES}

1. R. Barer, A. R. H. Cole, and H. W. Thompson, Nature 163, 198 (1949).

2. J. Mann and H. W. Thompson, Proc. Roy. Soc. A211, 168 (1952).

3. S. Krimm and G. B. B. M. Sutherland, Symposium on Molecular Structure and Spectroscopy, Columbus, Ohio, 1952.

4. R. G. J. Miller and H. A. Willis, Trans. Faraday Soc. 49, 133 (1953).

5. G. J. Weston, Chem. and Ind. p. 604 (1954).

6. W. H. Cobbs, Jr., and R. L. Burton, J. Polymer Sci. 10, 275 (1953).

7. R. G. J. Miller and H. A. Willis, $J$. Polymer Sci. 19, 485 (1956).

8. R. de P. Daubeny, C. W. Bunn, and C. J. Brown, Proc. Roy. Soc. A226, 531 (1954).

9. I. M. WARD, Chem. and Ind. p. 905 (1956).

10. I. M. WARD, Chem. and Ind. p. 1102 (1957).

11. B. SEIDEL, Z. Elecktrochem. 62, 214 (1958).

12. D. Patterson and I. M. Ward, Trans. Faraday Soc. 63, 291 (1957).

13. C. Y. Liang and S. Krimm, J. Chem. Phys. 27, 327 (1957).

14. C. Y. Liang and S. Krimm, J. Chem. Phys. 27, 1437 (1957).

15. M. C. TовIN, J. Phys. Chem. 61, 1392 (1957).

16. M. C. Toвin, J. Chem. Phys. 23, 891 (1955). 
17. C. Y. Liang, S. Krimm, and (x. B. B. M. Sutilerland, J. ('hem. Phys. 25, 543 (1956).

18. C. Y. Liang, J. Mol. Spectroscopy 1. 61 (1957).

19. W. W. Daniels and R. E. Kitson, J. Polymer Sci. 33, 161 (1958).

20. S. Bhagavantum and T. Venkatarayude, "Theory of Groups and its Application to Physical Problems," Andhra University, Waltair, India, 1951.

21. D. F. Hornig, J. Chem. Phys. 16, 1063 (1948).

22. C. Y. Liang and S. Krimm, J. Polymer Sci. 27, 241 (1958).

23. K. S. Pitzer and D. H. Scott, $J$. Am. Chem. Soc. 65, 803 (1943).

24. D. H. Whiffen, Phil. Trans. Roy. Soc. A248, 131 (1955).

25. N. Herzfeld, J. W. Hobden, C. K. Ingold, and H. G. Poole, J. Chem. Soc. p. 272 (1946).

26. C. R. Bailey, S. C. Carson, R. R. Gordon, and C. K. Ingold, J. Chem. Soc. p. 288 (1946).

27. S. Mizushima, "Structure of Molecules and Internal Rotation," p. 33. Academic Press, New York, 1954.

28. K. W. F. Konlrausch, "Ramanspektren," p. 177. Akademische Verlagsgesellschaft Becker and Erler, Leipzig, 1943.

29. R. I). Matr and D. F. Hornta, J. Chem. Phys. 17, 1236 (1949).

30. E. Herz and J. Wagner, Monatsh. Chem. 76, 93 (1946).

31. E. Herz, K. W. F. Kohlrausch, and R. Vogel, Monatsh. Chem. 76, 200 (1946).

32. A. R. H. Cole And H. W. Thompson, Trans. Faraday Soc. 46, 103 (1950).

33. R. R. Randle and D. H. Whiffen, "Molecular Spectroscopy," George Sell, ed., p. 111. Institute of Petroleum, London, 1955.

34. E. E. Ferglson, R. L. Hudson, J. R. Nielsen, and D. C. Smith, J. Chem. Phys. 21, 1457 (1953).

35. C. M. Richards and J. R. Nielsen, J. Opt. Soc. Am. 40, 438 (1950).

36. E. K. Plyler, Disc. Faraday Soc. 9, 100 (1950).

37. T. Shimanouchi, Y. Kakilti, and I. Gamo, J. Chem. Phys. 25, 1245 (1956).

38. D. H. Whiffen, Spectrochim. Acta 7, 253 (1955).

39. A. Pongratz and R. Seka, Monatsh. Chem. 66, 307 (1935).

40. J. LeComte, Disc. Faraday Soc. 9, 125 (1950).

41. J. K. Wilmshurst, J. Mol. Spectroscopy 1, 201 (1957).

42. H. W. Thompson and P. Torkington, J. Chem. Soc. p. 640 (1945).

43. G. Herzber(x, "Infrared and Raman Spectra," p. 174. Van Nostrand, New York, 1945.

44. S. Krimm, C. Y. Liang and G. B. B. M. Sutherland, J. Chem. Phys. 25, 549 (1956).

45. B. Nolin and R. N. Jones, Can. J. Chem. 34, 1392 (1956).

46. J. K. Brown and N. Sheppard, Trans. Faraday Soc. 48, 128 (1952).

47. W. H. T. Davison, J. Chem. Soc. p. 3270 (1955).

48. S. Krimm and C. Y. Liang, J. Polymer Sci. 22, 95 (1956).

49. S. Krimm, C. Y. Linng, and G. B. B. M. Sutherland, J. Polymer Sci. 22, 227 (1956).

50. O. Theimer, J. Chem. Phys. 27, 1041 (1957).

51. C. Y. Liang and S. Krimim, J. Polymer Sci. 31, 513 (1958).

52. C. W. Bunn, J. Polymer Sci. 16, 323 (1955).

53. D. Grime and I. M. WARD, Trans. Faraday Soc. 54, 959 (1958). 